\title{
Effect of heat-treatment on the hardness and mechanical properties of Boron Alloyed Steel
}

\author{
Mohammad Raffik bin Khiyon ${ }^{1}$, Salwani Mohd Salleh ${ }^{1, *}$ \\ ${ }^{1}$ Faculty of Mechanical Engineering, Universiti Malaysia Pahang (UMP), 26600 Pekan, Pahang, \\ Malaysia
}

\begin{abstract}
In an automotive industry, hot stamped, die quenched structural components have been widely used to provide extra protection against crash intrusion. Boron alloyed steel exhibit limited ductility, but it also promotes improvement in impact performance. This study analyzed the effect of cooling rate on the hardness and energy absorption. Selfquenched specimens were heated to $850^{\circ} \mathrm{C}$ and cooled in air of room temperature, water at room temperature and cold water. Vickers hardness test and tensile test was then carried out to analyze the effect of different quenching rate. Self-quenched specimens were compared to the properties of the die-quenched specimens obtained from commercial automobile body. Result shows that boron steel with the highest cooling rate has the highest value of hardness but low in strength.
\end{abstract}

\section{Introduction}

Steel manufacturers produce alloy boron steels that have undergone heat treatment, including quenching or quenching and tempering at low temperatures to attain high resistance to dynamic loads [1]. The adding of boron significantly increases the hardenability and strength of low and medium carbon steel was already observe in the year 1930s.

The demand in automotive industry to reduce the vehicle weight while considering the safety have rapidly increase the manufacturing of lightweight body parts from ultrahighstrength steels (UHSS). The process of forming this ultrahigh-strength steel is limited by low formability and considerable spring back. To overcome this problem, boron has been used as an alloying element for alloy steel. It is a vital material that plays an important role as it has strong and hard properties [2]. Thus, when the strength is increased, the size of the steel can be decreased and the weight will become lighter.

The desired mechanical properties and microstructure suitable for the specific purpose can be reached, by selecting the parameters of heat treatment of these steels $[3,4]$. This would allow them to extend their range of applications. However, the different

*Corresponding author: salwani@ump.edu.my 
microstructures can cause different mechanical properties, require careful decision making to define the application of these steels in many states of heat treatment. Thus, this study the effect of heat-treatment on the hardness and mechanical properties of boron alloyed steel.

\section{Experimental setup}

\subsection{Specimens}

Specimens are made of boron alloyed steel. This boron alloy steel grade 22MnB5 belongs to the product category of quenched and tempered steels, and features outstanding strength after heat treatment. The materials strength is propagated by adding a small fraction of boron to the carbon, manganese and chromium composition. Table 1 below shows the chemical composition of boron alloyed steel 22MnB5 that has been used in this research.

Table 1. Chemical composition of $22 \mathrm{MnB} 5$.

\begin{tabular}{|c|c|}
\hline Chemical Element & Percentage (\%) \\
\hline Carbon, $\mathrm{C}$ & 0.250 \\
\hline Silicon, Si & 0.400 \\
\hline Manganese, $\mathrm{Mn}$ & 1.350 \\
\hline Phosphorus, $\mathrm{P}$ & 0.023 \\
\hline Sulphur, S & 0.010 \\
\hline Aluminium, Al & 0.080 \\
\hline Nitrogen, $\mathrm{N}$ & 0.010 \\
\hline Chromium, Cr & 0.250 \\
\hline Boron, B & 0.004 \\
\hline
\end{tabular}

Different types of specimens tested are notated as: Blanked specimens (specimen-B); Die-quenched specimens (specimen-HPF), Blanked specimens that are heated and cooled at Room Temperature (specimen-RT); Blanked specimens that are heated and cooled in room temperature water (specimen-WRT); and Blanked specimens that are heated and cooled in cold water (specimen-WC). A total of 9 specimens were used in this heat treatment. First, all the specimen was heated in the furnace up to $900{ }^{\circ} \mathrm{C}$ for 2 hours. Secondly, the initial temperature of the specimen was taken by using infrared thermometer (range $-50{ }^{\circ} \mathrm{C}-1150$ ${ }^{\circ} \mathrm{C}$ ). Then, three of the specimen was taken out and cooled at room temperature. Another three specimens was taken out and cooled in water at room temperature $\left(25{ }^{\circ} \mathrm{C}\right)$ for 5 seconds and the final temperature of the specimen was taken. Then, last three specimens was taken out and cooled in cold water $\left(5^{\circ} \mathrm{C}\right)$ for 5 seconds and the final temperature of the specimen was taken. The temperature was taken to calculate the cooling rate for each type of quenching process in both type of water.

\subsection{Experimental procedures}

Vickers test was done based on the ASTM E384 to determine the hardness of each specimen. Since the material is in form of sheet, which is used for hot stamping, it is important to study the behaviour of the rolled sheet using tensile test. For the tensile testing, boron steel plate were cut into dimension as specified in ASTM 08M. All of the specimens 
were tested subjected to three velocities of the top platen plate, $3 \mathrm{~mm} / \mathrm{min}, 6 \mathrm{~mm} / \mathrm{min}$ and 9 $\mathrm{mm} / \mathrm{min}$.

\section{Results and discussion}

There are two types of testings that was conducted in this research which is the Hardness Test (Vickers) and Tensile Test. Both test conducted based on the ASTM. Both tests consist of control specimen of 22MnB5 with different type of treatment that has been done.

\subsection{Hardness test result}

Vickers Hardness test is carried out to obtain the hardness. Pyramid diamond indenter is pressed at 7 points for an interval of $0.2 \mathrm{~mm}$ for each of specimen types. The graph for this test were summarized in Figure 1 below.
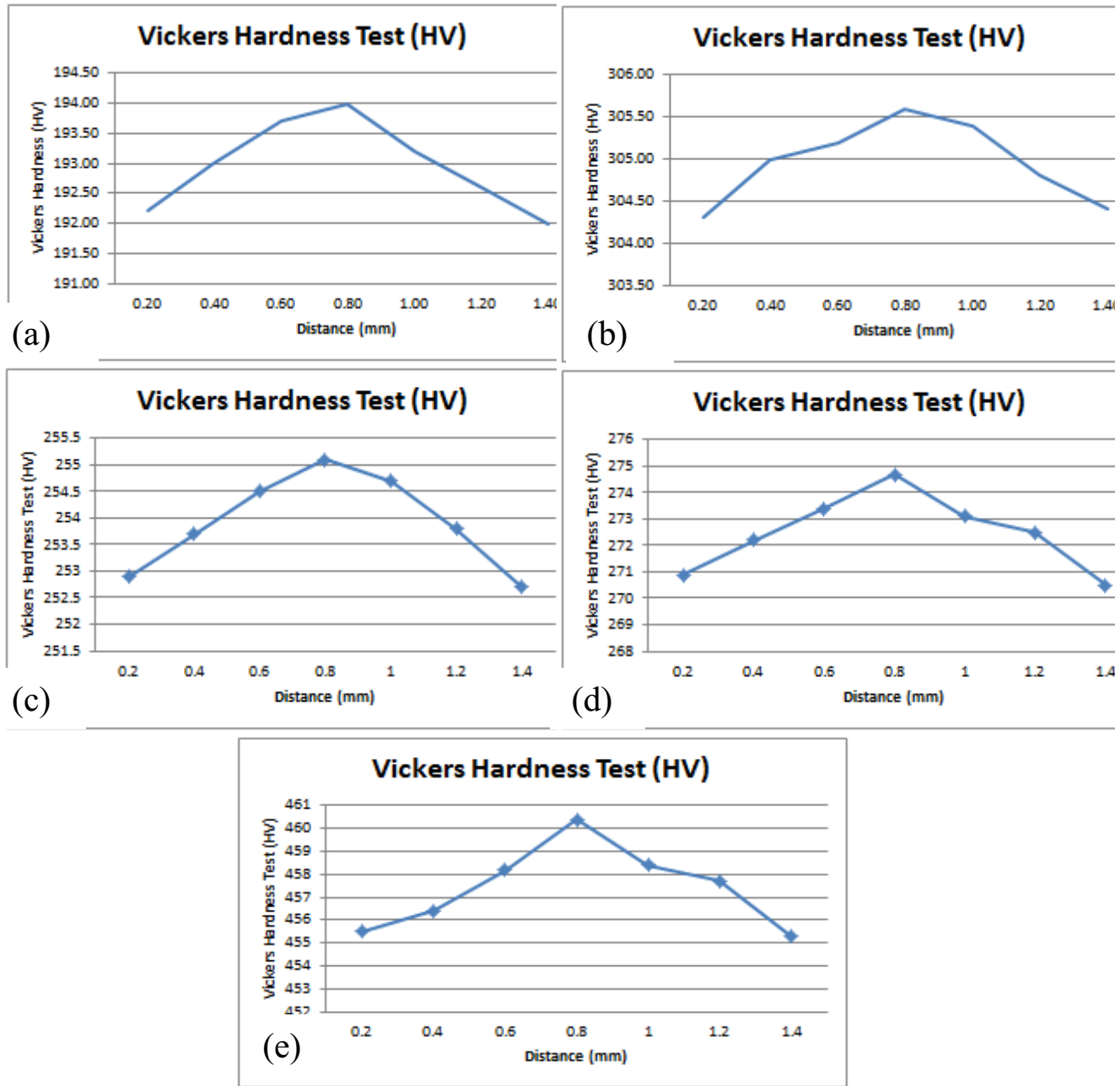

Fig. 1. Vickers Hardness test result for (a) specimen-B (b) specimen-HPF (c) specimen--RT (d) specimen-WRT and (e) specimen-WC. 
Based on Fig. 1, the average Vikers Hardness for each of the specimens are: $192.96 \mathrm{HV}$ (specimen-B); $304.19 \mathrm{HV}$ (specimen-HPF), 253.91 (specimen-RT); 272.4HV (specimenWRT); and $457.93 \mathrm{HV}$ (specimen-WC). The Vickers hardness test results for $22 \mathrm{MnB} 5$ shows that the highest value for hardness is for specimen-OWC that is and the lowest value is for specimen-O. Specimen-O has the lowest Vickers Hardness value because the microstructure for this steel contains a mixture of pearlite phase, ferrite and small amount of carbide. It has no martensitic in the microstructure. For other types of $22 \mathrm{MnB} 5$, it has martensitic in the microstructure because of the process of annealing. The hardness of the steel depends on the amount of martensitic on it and it also depends on the grain size, the smaller the grain size, the higher the value of hardness and strength. The size of the grain size depends on the cooling rate of the specimen. The faster the cooling rates, the smaller the size of the grain size. Specimen-OWC has the fastest cooling rate which is $122.6{ }^{\circ} \mathrm{C} / \mathrm{s}$. The fine grain of the martensitic structure of these steels creates their characteristic features of high toughness, strength.

\subsection{Tensile test result}

In this analysis, properties that are directly measured via a tensile test are ultimate tensile strength, and Young's modulus. This tensile test was done based on ASTM E8/E8M - 13 which is the Standard Test Methods for Tension Testing of Metallic Materials. The reading for tensile test was taken with three different velocities which is 3,6 and $9 \mathrm{~mm} / \mathrm{min}$. The graph for all results was summarized in Table 2

Based on all the results obtained, the best steel is 22MnB5 HPF. 22MnB5 HPF has good Tensile Stress and good Young Modulus compare to other 22MnB5. For as-received $22 \mathrm{MnB} 5$ and 22MnB5 RT, it has good Young Modulus but poor Tensile Stress. For $22 \mathrm{MnB} 5 \mathrm{WRT}$, it has good Tensile Stress but poor Young Modulus and for 22MnB5 CW it has poor Tensile Stress and Young Modulus. Poor Young Modulus will make the steel becomes less flexible and become more to brittle. Brittle materials cannot absorb the impact applied on it and it will break easier. Poor Tensile Stress means that the steels are not strong enough. Weak materials cannot hold the high Tensile Stress applied on it and it also will break easier.

Table 2. Stress-strain curves and fractured specimens.

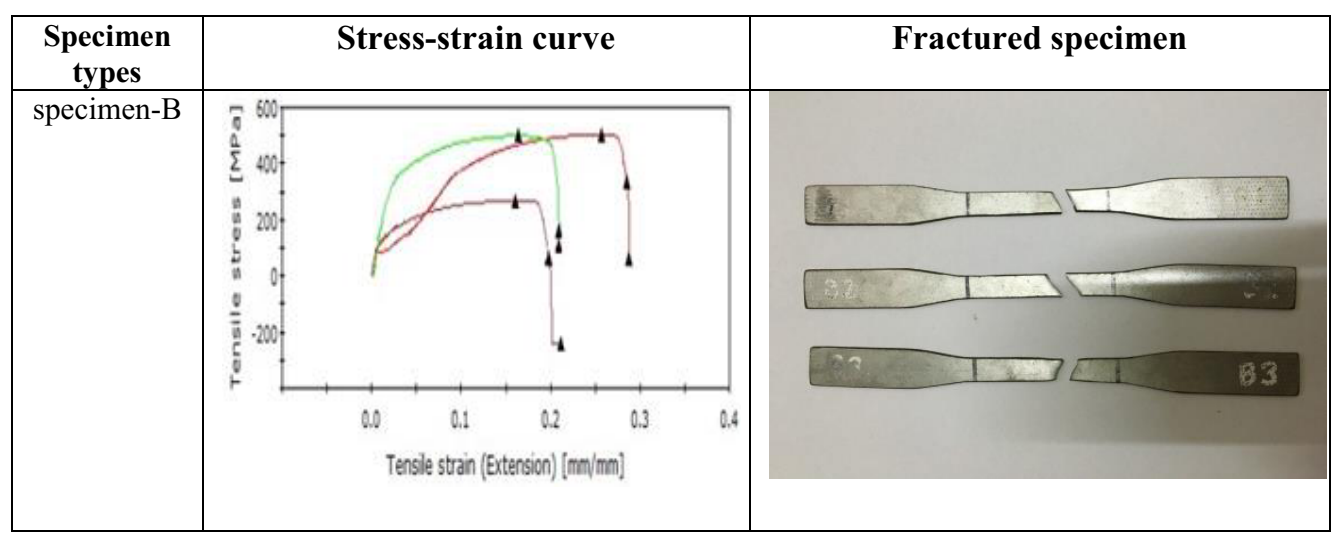




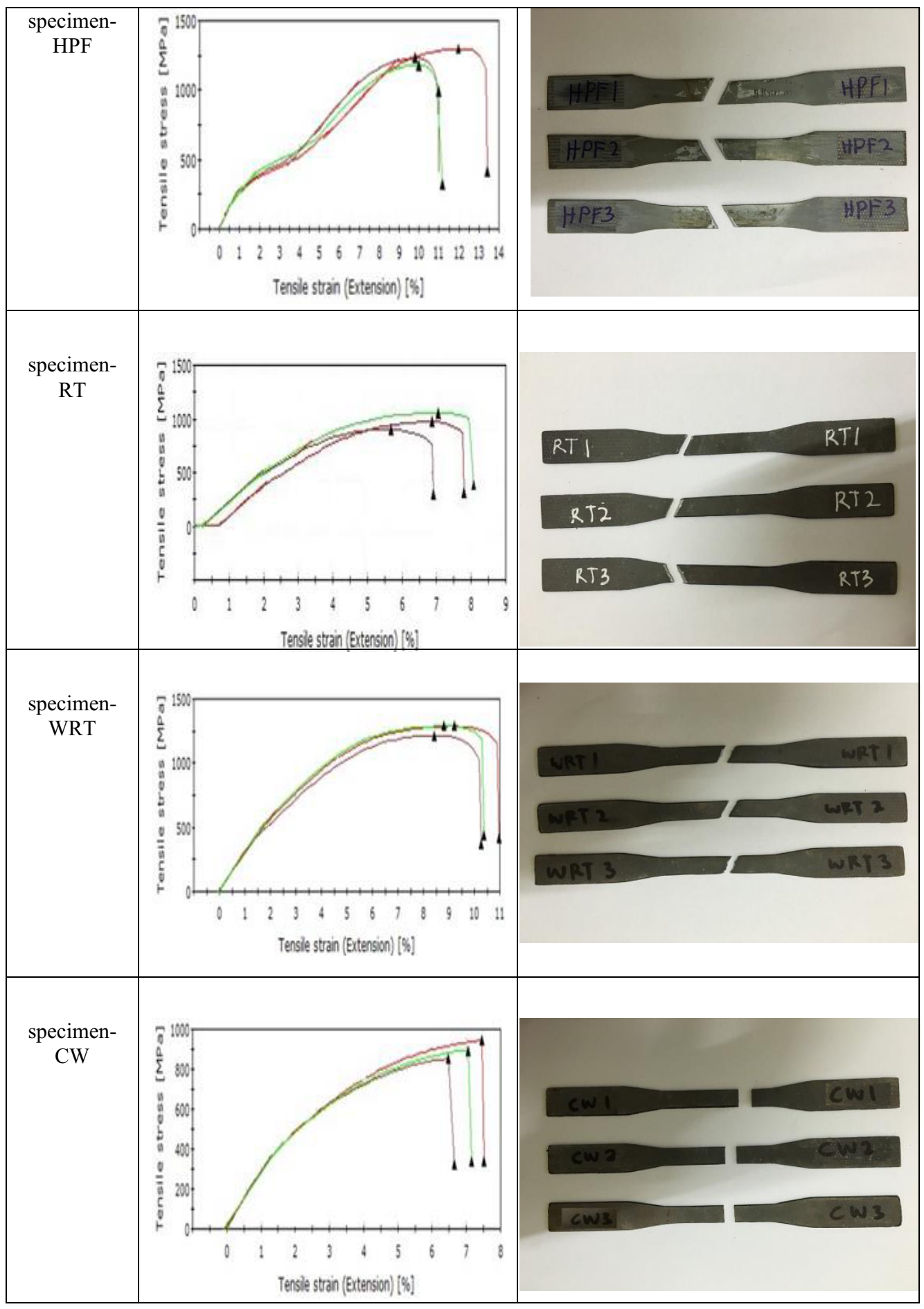

Legend: 


\section{Conclusions}

As conclusion, the heat treatment done to the $22 \mathrm{MnB} 5$ with different type of quenching process has portrayed an encouraging result, particularly in the hardness of the $22 \mathrm{MnB} 5$. The higher the cooling rate of the quenching, the smaller the size of the grain size. Hence, it will increase the hardness of the steel. When the cooling rate is very high, it will increase the strength of the steel but it will reduce the toughness and the ductility of the steel. Higher cooling rate tends to make the steel become less flexible and more brittle.

The authors would like to thanks Universiti Malaysia Pahang for providing laboratory facilities and financial assistance under project no. RDU1303114.

\section{References}

1. H. So, D. Fasmann, H. Hoffmann, R. Golle, M. Schaper, An investigation of the blanking process of the quenchable boron alloyed steel 22MnB5 before and after hot stamping process, Journal of Materials Processing Technology 212 (2012) 437-449.

2. M. Naderi, V. Uthaisangsuk, U. Prahl, W. Bleck, A Numerical and Experimental Investigation into Hot Stamping of Boron Alloyed Heat Treated Steels, steel research int. 79 (2008) No. 2.

3. N. Aziz, S.N. Aqida, Optimization of quenching process in hot press forming of $22 \mathrm{MnB} 5$ steel for high strength properties for publication, Materials Science and Engineering 50 (2013).

4. P. Hu, D. Shi, L. Ying, G. Shen, W. Liu, The finite element analysis of ductile damage during hot stamping of 22MnB5 steel, Materials and Design 69 (2015) 141-152. 